\title{
Determination of gold leaf thickness using X-ray fluorescence spectrometry: accuracy comparison using analytical methodology and Monte Carlo simulations
}

\author{
Sofia Pessanha ${ }^{1}$, Ignasi Queralt ${ }^{2}$, Maria Luísa Carvalho $^{1}$, Jorge Miguel Sampaio ${ }^{3}$ \\ ${ }^{1}$ LIBPhys-UNL - Laboratório de Instrumentação, Engenharia Biomédica e Física da Radiação; Faculdade \\ de Ciências e Tecnologia da Universidade Nova de Lisboa, 2829-516, Caparica, Portugal \\ ${ }^{2}$ Dept. of Geosciences, IDAEA-CSIC, Jordi Girona St., 18-26, 08034 Barcelona, Spain \\ ${ }^{3}$ LIP - Laboratory for Instrumentation and Experimental Particle Physics, Av. Prof. Gama Pinto, n.2 \\ Complexo Interdisciplinar (3is) 1649-003 Lisboa, Portugal
}

\begin{abstract}
In this work, we compared the accuracy of gold leaves thickness determination using Xray Fluorescence (XRF) setups for different X-ray excitation sources. The sources used consisted on: a) direct Bremsstrahlung from an Amptek Mini-X X-ray tube with Rh target, b) partially monochromatized radiation of the same X-ray tube using combination of $\mathrm{Al}$ and $\mathrm{Ag}$ filters and, c) monochromatic radiation using secondary target, in a portable setup with triaxial geometry. The performance of the used setups was compared using model samples made with gold foil standard reference materials of known thicknesses (1, 2 and $2.5 \mu \mathrm{m})$. Thickness determination was based on the selective attenuation that the different energies of a given element of an under-layer undergo in the gilded layer. Ideally, as it can be expected from physics fundamentals, monochromatic radiation is needed for improved accuracy. However, considering the difficulties in using monochromatic radiation in portable instrumentation applicable in Cultural Heritage studies, filtered radiation can also be used for reliable results. Moreover, Monte Carlo simulations of the portable setup with conventional planar geometry were performed for comparison and for future application in more complex samples.
\end{abstract}

Keywords: XRF; gilding; thickness determination; Cultural Heritage; Monte Carlo simulations 


\section{Introduction}

When studying gilded artworks, or other kind of stratigraphy, the determination of the gold leaf thickness is, together with the alloy composition, one of the main objectives. Layer thickness determination and compositional analysis of thin coatings and nanolayers of modern and advanced materials can be routinely made by laboratory XRF instrumentation using an adequate software (Roessiger, 2006) which not always can be carried to the museum or archaeological site. Gilding is the deposition of a gold layer on to a surface of another material, and its use has been reported since $3000 \mathrm{BC}$.

Gilding with gold leaf has been applied in several substrates considered of artistic and cultural importance, namely paper and leather (Hayez et al., 2004; Pessanha et al., 2012), clay-based (Wang et al., 2014) or ivory (Rozalen and Ruiz Gutierrez, 2015) sculptures and even wall paintings (Cesareo et al., 2008; Katsibiri and Boon, 2004). There is, however, a great number of artifacts made of copper-based alloys that were entirely gilded to simulate solid gold (Andrade et al., 2005; Cesareo et al., 2010; Trojek and Hložek, 2012) or partially gilded for decorative purposes (Veiga et al., 2015). There are several strategies to evaluate gilding of an artwork. Scanning Electron Microscopy (SEM) imaging (Katsibiri and Boon, 2004; Rozalen and Ruiz Gutierrez, 2015; Veiga et al., 2015), and Proton Induced X-ray Emission (Andrade et al., 2005; Ortega-Feliu et al., 2010) are often used to determine the thickness of coatings in art and Cultural Heritage. However, sampling is required in the first technique, while the second only can be applied in small objects that can be moved to the laboratory. X-ray fluorescence techniques are more suitable for this task because they are non-destructive and portable instrumentation is available. Cesareo et al. (Cesareo, 2003; Cesareo et al., 2009) have proven that the ratio of the intensities of the characteristic lines of an element in the substrate depends on and can be used to measure the thickness of gilding. Similar approach was used by Trojek et al. (Trojek and Hložek, 2012) in the study of $18^{\text {th }}$ century Altar decorations and by Pessanha et al. (Pessanha et al., 2014a) in the analysis of an $16^{\text {th }}$ century illuminated manuscript. This method relied on the comparison with the analysis of the substrate without coating, which is, sometimes, not possible. This was the case of the study and comparison of the gold leaf in a set on Namban folding screens, where only the different characteristic lines of Au were determined and compared in order to assess different thicknesses (Pessanha et al., 2014b). Buccolieri et al. (Buccolieri et al., 2018) used the 
total attenuation of the radiation coming from an ${ }^{241} \mathrm{Am} \gamma$-ray source for the determination of the thickness of a wreath of gold leaves from the National Archaeological Museum of Taranto, while Ferreti et al. (Ferretti et al., 2013) derived the thickness of gilded silver using the mass fractions for $\mathrm{Ag}-\mathrm{K}_{\alpha}$ and $\mathrm{Ag}-\mathrm{K}_{\beta}$ in the XRF spectra. These methods were designed to be implemented using monochromatic X-ray source, however this is not the case in most circumstances, where only some kind of filtering is used to partially reduce background or even no filtering and the direct Bremsstrahlung from the tube is applied for analysis.

In this work, the application of two evaluation methodologies based on the selective attenuation of radiation in a gold foil will systematically compared by using 2 different setups and different incident sources: direct Bremsstrahlung from the X-ray tube, partially monochromatized radiation using combinations of filters in the output of the X-ray tube and monochromatic radiation using secondary target on model samples. Furthermore, Monte Carlo simulations of the setup, using filter combinations were performed in order to further evaluate the suitability of this approach to gold leaf thickness determination.

\section{Methodology}

Two similar approaches have been demonstrated by Cesareo et al. (Cesareo, 2003; Cesareo et al., 2009) and used profusely for the determination of the thickness of gold coatings (Cesareo et al., 2013, 2004; Pessanha et al., 2014a). The first one relates the different characteristic lines of $\mathrm{Au}$ due to their differentiated attenuation in the layer regarding the thickness. Considering the $\mathrm{L} \alpha / \mathrm{L} \beta$ intensity ratio, it would be maximum for an infinitely thin sample and decrease exponentially with increasing thickness until it plateaus for an infinitely thick sample (Sitko, 2009), according to equation 1:

$$
\left(\frac{L_{\alpha}}{L_{\beta}}\right)=\left(\frac{L_{\alpha}}{L_{\beta}}\right)_{0}\left(\frac{\varepsilon\left(E\left(L_{\alpha}\right)\right)}{\varepsilon\left(E\left(L_{\beta}\right)\right)}\right)\left[\frac{\left(\mu_{0}+\mu_{2}\right)}{\left(\mu_{0}+\mu_{1}\right)}\right]\left[\frac{1-e^{-\left(\mu_{0}+\mu_{1}\right) d}}{1-e^{-\left(\mu_{0}+\mu_{2}\right) d}}\right]
$$

where,

$\left(\frac{L_{\alpha}}{L_{\beta}}\right)_{0}$ is the intensity ratio for an infinitely thin sample (Seltzer, 1989);

$\varepsilon(\mathrm{E})$ is the detector efficiency for a given energy;

$\mu_{0}$ is the linear attenuation coefficient $\left(\mathrm{in} \mathrm{cm}^{-1}\right.$ ) of $\mathrm{Au}$ at incident energy $\mathrm{E}_{0}$; $\mu_{1}$ is the linear attenuation coefficient (in $\mathrm{cm}^{-1}$ ) of $\mathrm{Au}$ at energy of $\mathrm{L} \alpha$ emission line (9.71 $\mathrm{keV})$; 
$\mu_{2}$ is the linear attenuation coefficient (in $\mathrm{cm}^{-1}$ ) of Au at energy of $\mathrm{L} \beta$ emission line (11.4 $\mathrm{keV})$;

$\mathrm{d}$ is path length of the characteristic radiation (in $\mathrm{cm}$ ) and $d=\frac{x}{\cos \theta}$ where $\mathrm{x}$ is the thickness of the layer and $\theta$ is the angle between the detector and the normal to the sample. Another technique, used when the gilding under-layer can be assessed, is to compare the characteristic lines of substrate with and without attenuation in the gilding. Considering a substrate of a copper-based alloy covered with gold leaf, the characteristic lines of the substrate are attenuated in the gold layer differently, according to their mass-attenuation coefficient, as can be seen in equation 2 :

$$
\left(\frac{K_{\alpha}}{K_{\beta}}\right)=\left(\frac{K_{\alpha}}{K_{\beta}}\right)_{\text {s.a. }} e^{-\left(\mu_{1}-\mu_{2}\right) \rho_{A u} d_{A u}} \quad \text { eq.(2) }
$$

where:

$(\mathrm{K} \alpha / \mathrm{K} \beta)_{\text {s.a. }}$ is the intensity ratio of the characteristic lines of $\mathrm{Cu}$ in copper due to selfattenuation effects;

$\mu_{1}$ is the mass attenuation coefficient (in $\mathrm{cm}^{2} \cdot \mathrm{g}^{-1}$ ) of $\mathrm{Cu}$ at $8.04 \mathrm{keV}$;

$\mu_{2}$ is the mass attenuation coefficient (in $\mathrm{cm}^{2} \cdot \mathrm{g}^{-1}$ ) of $\mathrm{Cu}$ at $8.9 \mathrm{keV}$;

$\rho_{A u}$ is the density $\left(\right.$ in $\mathrm{g} \cdot \mathrm{cm}^{-3}$ ) of $\mathrm{Au}$;

$\mathrm{d}_{\mathrm{Au}}$ is the path length (in cm) and $d=\frac{x}{\cos \theta}$ where $\mathrm{x}$ is the thickness of the layer and $\theta$ is the angle between the detector and the normal to the sample.

\section{Experimental}

\subsection{Materials}

A set of three 99.9\% pure Au square foils (from Goodfellow Inc., Huntingdon, UK) with $25 \times 25 \mathrm{~mm}$ in size and thickness of 1,2 and $2.5 \mu \mathrm{m}( \pm 25 \%)$ were used.

The under layer consisted of a plate, $\sim 3 \mathrm{~mm}$ thick, of uncertified nearly pure copper metal. Quantification of XRF spectra, obtained with a benchtop commercial setup M4Tornado, using Fundamental parameter method for bulk samples (Pessanha et al., 2015), determined $99.9 \% \mathrm{Cu}$ with traces of $\mathrm{Fe}$ and $\mathrm{Pb}$.

\subsection{Portable setup with triaxial geometry - p3XRF}


125 An experimental setup was assembled using a sided window X-ray tube with a Mo anode,

126 OXFORD XTF5011 ( $\max 50 \mathrm{kV}, 1 \mathrm{~mA}$ ) and a Silicon Drift Detector, thermoelectrically 127 cooled (60EX, Vortex) (FWHM at $160 \mathrm{eV}$ at $\left.\mathrm{Fe}-\mathrm{K}_{\alpha}\right)$, with an active area of $50 \mathrm{~mm}^{2}$ and 128 a $25 \mu \mathrm{m}$ thickness Be window. Monochromatization and reduction of the Bremstrahlung 129 from the tube was obtained using a secondary Yttrium target disk (99\% purity, $1.0 \mathrm{~mm}$ 130 thickness, $25.0 \mathrm{~mm}$ diameter, GoodFellow Inc., Huntingdon, UK) in triaxial geometry as 131 it was described in a previous work (Pessanha et al., 2017). The spot size was measured with a radiographic film producing an ellipsoid image with $17 \mathrm{~mm} \times 12 \mathrm{~mm}$. Spectra were acquired using PI-Spec $\mathrm{A}^{\circledR}$ software and the X-ray generator was operated at $50 \mathrm{kV}$, $1 \mathrm{~mA}$ during $300 \mathrm{~s}$.

The XRF portable setup consists of an X-ray generator (Mini-X, Rh target, $50 \mathrm{kV}, 200$ $\mu \mathrm{A}$, max. from Amptek Inc., Bedford, USA) and silicon PIN detector (XR-100CR, 7 mm² detection area, $500 \mu \mathrm{m}$ thickness and a $12.5 \mu \mathrm{m}$ Be window, from Amptek Inc., Bedford, USA).

The angle between the incident and the emitted beam is $90^{\circ}$ in order to obtain high reduction of the background due to Compton scattering. The energy resolution is $190 \mathrm{eV}$ at $5.9 \mathrm{keV}$. Spectra were acquired using PocketMCA software and the X-ray generator was operated at $40 \mathrm{kV}$ and $40 \mu \mathrm{A}$ during $200 \mathrm{~s}$. Partial monochromatization was achieved using a combination of filters provided by Amptek $(2 \times 1 \mathrm{~mm} \mathrm{Al}+250 \mu \mathrm{m} \mathrm{Ag})$. Knife edge method determined a spot size of $1.1 \mathrm{~mm}$.

Spectra analysis, for both spectrometers was performed using the LabSpec ${ }^{\circledR}$ software package (5.58 version). Intensities were determined by integrating the full area under the curve. Efficiency curves for SDD and SiPIN detectors were taken from the manufacturer's datasheets. 
statistics, instead of simulating the whole setup since the acceleration of electrons into the anode, a direct measurement of the X-ray tube's spectrum after filtering was used as input in the simulation file after deconvolution with the detector's efficiency. The absorption energies, elastic scattering parameters and cutoff energies were set as the default recommendation considering the maximum energy of particles in the simulation (EPMAX) of $40 \mathrm{keV}$. The output spectra were then convoluted with the efficiency of the detector and an energy dependent Gaussian function for the broadening of the peaks obtained by determining the Full Width at Half Maximum (FWHM) of several monoelemental samples.

\section{Results and discussion.}

Figures 1 and 2 represent the theoretical plots of equation 1 for the different setups. Furthermore, they present the experimental results for $\mathrm{Au}\left(\mathrm{L}_{\alpha} / \mathrm{L}_{\beta}\right)$ intensity ratios determined for the 3 Standard Reference Materials, with the different combination of excitation sources, corrected for the efficiency of the detector and absorption in air (Sögüt, 2004). As can be seen, the experimental results obtained for the setup with monochromatic radiation are within 1 standard deviation of the theoretical curve.

Regarding the results obtained for the other setup, the use of direct excitation from the source, without filtering produces higher intensity ratios and presents challenge to correlate with the theoretical curve. This divergence from the theoretical curve occurs because it was also plotted considering the anode's incident energy of Rh-K $\mathrm{K}_{\alpha}$, which does not correspond to the real incident spectrum. Full monochromatic radiation with the filters was not achieved, and additionally, incident X-rays will be hardened as the thickness of the layer increases.

The determined thicknesses of the three foils using the second approach (equation 2), again using both setups, as exhibited in table 1 .

As expected, the determined thicknesses are less accurate when using unfiltered radiation. The most accurate results were obtained using the p3XRF setup, with monochromatic radiation, with a maximum deviation of $5 \%$ respect to the certified value.

Regarding the use of filters, as employed in most published case studies mentioned in the introduction section, the deviation to the certified thickness is less than $12 \%$, with underestimated values. Regardless these deviations and considering the uncertainties, the obtained values are reliable and in accordance with the discrepancies found elsewhere (Lopes et al., 2016; Ortega-feliu et al., 2017). 
In Fig.3 are displayed the obtained results for $\mathrm{Cu}\left(\mathrm{K}_{\alpha} / \mathrm{K}_{\beta}\right)$ intensity ratios considering simulated samples of varying thicknesses of $100 \% \mathrm{Au}(0.1$ to $2.5 \mu \mathrm{m})$ over an infinitely thick layer of $\mathrm{Cu}(500 \mu \mathrm{m})$. The uncertainty contemplates the statistical uncertainty of the output simulated spectrum and uncertainty of the fitting of the curve using Labspec ${ }^{\circ}$ After fitting of the obtained curve considering equation 2, the value for $\mathrm{Cu}\left(\mathrm{K}_{\alpha} / \mathrm{K}_{\beta}\right)$ intensity ratio due to self-attenuation in the $\mathrm{Cu}$ layer was determined to be $6.87 \pm 0.03$.

\section{Conclusion}

The use of a non-destructive approach for gilding analysis is of utmost importance when dealing with Cultural Heritage and delicate objects of artistic value. This paper described the systematic comparison of two simple analytical approaches for the determination of the thickness of gildings using XRF instrumentation, for different excitation sources and instrumental design. As anticipated, the use of monochromatic radiation is paramount when great accuracy is needed in the calculations. However, in practice, most portable instrumentation for XRF does not comply with this requirement. Considering the obtained results, the use of filters for background reduction and partial monochromatization can be used as an alternative, quite accurate approach, for thickness determination when the characteristic lines of an element of the under-layer can be assessed and compared with and without gilding. On the other hand, performing these calculations without filtering the X-ray source would lead to deceptive results.

The modeling of this setup using Monte Carlo method also proved suitable for reproducing such simple stratigraphy as pure gold of varying thicknesses over a layer of infinitely thick copper. This approach can, hence, be used for the simulation of more complex samples and determination of gilding thickness without sampling or without the need for assessing the underlayer.

\section{Funding statement}

Financial support for this investigation was provided by Portuguese Foundation for Science and Technology (FCT) in the funding of LIBPhys-UNL (project UID/FIS/04559/2013). S. Pessanha also acknowledges FCT for the post-doc grant SFRH/BPD/94234/2013. I. Queralt acknowledges a sabbatical grant from the Ministry of Education of the Spanish Government (Ref. PRX16/00159). 


\section{References}

Andrade, E., Murillo, G., Policroniades, R., Acosta, L., 2005. IBA analysis of some precolumbian gilded-copper samples $240,570-575$.

Baró, J., Sempau J., Fernández-Varea, J.M., Salvat F., 1995. PENELOPE: na algorithm for Monte Carlo simulations of the penetration and energy loss of electrons and positrons in matter 100, 31-46.

Buccolieri, A., Degl'Innocenti, E., Cesareo, R., Castellano, A., Buccolieri, G., 2018. Non-invasive in-situ analysis of a wreath of gold leaves from the National Archaeological Museum of Taranto, Italy. Meas. J. Int. Meas. Confed. 126, 164167.

Cesareo, R., 2003. Non-destructive EDXRF-analysis of the golden haloes of Giotto's frescos in the Chapel of the Scrovegni in Padua. Nucl. Instruments Methods Phys. Res. Sect. B Beam Interact. with Mater. Atoms. 211, 133-137.

Cesareo, R., Brunetti, A., Ridolfi, S., 2008. Pigment layers and precious metal sheets by energy-dispersive x-ray fluorescence analysis. X-Ray Spectrom. 37, 309-316.

Cesareo, R., Bustamante, A.D., Fabian, J.S., Del Pilar Zambrano, S., Alva, W., Chero, L.Z., Del Carmen Espinoza, M.C., Rodriguez, R.R., Seclen, M.F., Gutierrez, F. V., Levano, E.B., Gonzales, J.A., Rizzutto, M.A., Poli, E., Calza, C., Dos Anjos, M., Pereira De Freitas, R., Lopes, R.T., Elera, C., Shimada, I., Curay, V., Castillo, M.G., Gigante, G.E., Ingo, G.M., Lopes, F., Holmquist, U., Diestra, D., 2013. Multilayered artifacts in the pre-Columbian metallurgy from the North of Peru. Appl. Phys. A Mater. Sci. Process. 113, 889-903.

Cesareo, R., Calza, C., Dos Anjos, M., Lopes, R.T., Bustamante, A., Fabian S., J., Alva, W., Chero Z., L., 2010. Pre-Columbian alloys from the royal tombs of Sipán; energy dispersive X-ray fluorescence analysis with a portable equipment. Appl. Radiat. Isot. 68, 525-528.

Cesareo, R., Castellano, A., Buccolieri, G., Quarta, S., Marabelli, M., 2004. Giotto in the Chapel of the Scrovegni: EDXRF analysis of the golden haloes with portable equipment. X-Ray Spectrometry. 33, 289-293.

Cesareo, R., Rizzutto, M.A., Brunetti, A., Rao, D. V., 2009. Metal location and thickness in a multilayered sheet by measuring $\mathrm{K} \alpha / \mathrm{K} \beta, \mathrm{L} \alpha / \mathrm{L} \beta$ and $\mathrm{L} \alpha / \mathrm{L} \gamma \mathrm{X}$-ray ratios. Nucl. Instruments Methods Phys. Res. Sect. B Beam Interact. with Mater. Atoms 267, 2890-2896.

F. Lopes, F.L. Melquiades, C. Appoloni, R. Cesareo, M. Rizzutto, T.F.S., 2016. 
Thickness determination of gold layer on pre-Columbian objects and a gilding frame, combining pXRF and PLS regression. X-Ray Spectrom. 45, 344-351.

Ferretti, M., Polese, C., Roldán García, C., 2013. X-ray fluorescence investigation of gilded and enamelled silver: The case study of four medieval processional crosses from central Italy. Spectrochim. Acta - Part B At. Spectrosc. 83-84, 21-27.

Hayez, V., Denoël, S., Genadry, Z., Gilbert, B., 2004. Identification of pigments on a 16th century Persian manuscript by micro-Raman spectroscopy. J. Raman Spectrosc. 35, 781-785.

Katsibiri, O., Boon, J.J., 2004. Investigation of the gilding technique in two postByzantine wall paintings using micro-analytical techniques B 59, 1593-1599.

Ortega-Feliu, I., Ager, F.J., Roldán, C., Ferretti, M., Juanes, D., Scrivano, S., Respaldiza, M.A., 2017. Nuclear Instruments and Methods in Physics Research B Multi-technique characterization of gold electroplating on silver substrates for cultural heritage applications. Nucl. Inst. Methods Phys. Res. B 406, 318-323.

Ortega-Feliu, I., Moreno-Suárez, A.I., Gómez-Tubío, B., Ager, F.J., Respaldiza, M.A., García-dils, S., 2010. Nuclear Instruments and Methods in Physics Research B A comparative study of PIXE and XRF corrected by Gamma-Ray Transmission for the non-destructive characterization of a gilded roman railing. Nucl. Inst. Methods Phys. Res. B 268, 1920-1923.

Pessanha, S., Alves, M., Sampaio, J.M., Santos, J.P., Carvalho, M.L., Guerra, M., 2017. A novel portable energy dispersive X-ray fluorescence spectrometer with triaxial geometry. J. Instrum. 12, P01014

Pessanha, S., Costa, M., Oliveira, M.I., Jorge, M.E.M., Carvalho, M.L., 2015. Nondestructive analysis of Portuguese "dinheiros" using XRF: overcoming patina constraints. Appl. Phys. A Mater. Sci. Process. 119, 1173-1178.

Pessanha, S., Guerra, M., Longelin, S., Le Gac, A., Manso, M., Carvalho, M.L., 2014a. Determination of gold leaf thickness in a Renaissance illumination using a nondestructive approach. X-Ray Spectrom. 43, 79-82.

Pessanha, S., Madeira, T.I., Manso, M., Guerra, M., Le Gac, A., Carvalho, M.L., 2014b. Comparison of gold leaf thickness in Namban folding screens using X-ray fluorescence. Appl. Phys. A Mater. Sci. Process. 116, 1053-1058.

Pessanha, S., Manso, M., Carvalho, M.L., 2012. Application of spectroscopic techniques to the study of illuminated manuscripts: A survey. Spectrochim. Acta Part B At. Spectrosc. 71-72, 54-61. 
Rozalen, M., Ruiz Gutierrez, A., 2015. A study of the origin and gilding technique of a Hispano-Philippine ivory from the XVIIth century. J. Archaeol. Sci. Reports 4, 17.

Seltzer, J.H.H. and S.M., 1989. Tables of X-Ray Mass Attenuation Coefficients and Mass Energy-Absorption Coefficients from $1 \mathrm{keV}$ to $20 \mathrm{MeV}$ for Elements $\mathrm{Z}=1$ to 92 and 48 Additional Substances of Dosimetric Interest.

Sitko, R., 2009. Spectrochimica Acta Part B Quantitative X-ray fl uorescence analysis of samples of less than 'in fi nite thickness ': Dif fi culties and possibilities 64, 1161-1172.

Söğ̈̈t, O., 2004. Dependence on average atomic number of coherent / incoherent scattering intensity ratios in compounds $87,15-23$.

Trojek, T., Hložek, M., 2012. X-ray fluorescence analysis of archaeological finds and art objects: Recognizing gold and gilding. Appl. Radiat. Isot. https://doi.org/10.1016/j.apradiso.2012.03.033

V. Roessiger, B.N., 2006. Analysis of layers, in: Beckhoff B, Kannigiesser B, Langhoff N, W.R. (Ed.), Handbook of Practical X-Ray Fluorescence Analysis. Springer, Berlin.

Veiga, A., Martins, D., Candeias, A.J., Mirão, J., Manhita, A., Miguel, C., Rodrigues, P., Ginja, J., 2015. Micro-analytical study of two 17th century gilded miniature portraits on copper. Microchem. J. 123, 51-61.

Wang, N., He, L., Egel, E., Simon, S., Rong, B., 2014. Complementary analytical methods in identifying gilding and painting techniques of ancient clay-based polychromic sculptures. Microchem. J. 114, 125-140.

.

9

0

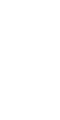

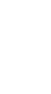


Figure captions:

329 Fig. 1 - Comparison of the theoretical dependence of $\mathrm{Au}\left(\mathrm{L}_{\alpha} / \mathrm{L}_{\beta}\right)$ intensity ratio and the thickness of $A u$ layer for the $\mathrm{p} 3 \mathrm{XRF}$ setup and the experimental results. The incident radiation for theoretical curve was set to $14.9 \mathrm{keV}\left(\mathrm{Y}-\mathrm{K}_{\alpha}\right)$. Vertical error bars correspond to 1 standard deviation for 6 measurements.

332 Fig. 2 - Comparison of the theoretical dependence of $A u\left(L_{\alpha} / L_{\beta}\right)$ intensity ratio and the thickness of $A u$ 333 layer for the portable setup with planar geometry considering (considering incident energy of Rh - $\mathrm{K}_{\alpha}(20.2$ $334 \mathrm{keV}$ )), the experimental results (vertical error bars correspond to 1 standard deviation for 6 measurements) and Monte Carlo simulations of the setup (vertical error bars correspond to the uncertainty of the method).

336 Fig. 3 - Comparison of the simulated dependence of $\mathrm{Cu}\left(\mathrm{K}_{\alpha} / \mathrm{K}_{\beta}\right)$ intensity ratio and the thickness of $\mathrm{Au}$ layer for the portable setup with conventional geometry (vertical error bars correspond to the uncertainty of the method) and the experimental results (vertical error bars correspond to 1 standard deviation for 6 measurements). Fitted curve using exponential function is also presented.

344 Table 1. Mean thicknesses $(\mu \mathrm{m})$ determined for the different configurations. The uncertainty corresponds to one standard deviation over 6 measurements. $\Delta$ corresponds to the relative deviation to the certified value (in \%).

\begin{tabular}{|c|c|c|c|c|c|c|}
\hline \multirow[b]{2}{*}{ Thickness $(\mu \mathrm{m})$} & \multicolumn{4}{|c|}{ Portable } & \multirow{2}{*}{$\begin{array}{c}\text { p3XRF } \\
\text { (Monochromatic) }\end{array}$} & \multirow{2}{*}{$\underset{(\%)}{\Delta}$} \\
\hline & No filter & $\begin{array}{c}\Delta \\
(\%)\end{array}$ & filter $\mathrm{Al} / \mathrm{Ag}$ & $\begin{array}{c}\Delta \\
(\%)\end{array}$ & & \\
\hline $1.00 \pm 0.25$ & $1.5 \pm 0.2$ & 40 & $0.9 \pm 0.1$ & 10 & $1.0 \pm 0.1$ & $<1$ \\
\hline $2.0 \pm 0.5$ & $2.2 \pm 0.2$ & 10 & $1.8 \pm 0.2$ & 10 & $2.1 \pm 0.1$ & 5 \\
\hline $2.5 \pm 0.6$ & $3.0 \pm 0.3$ & 20 & $2.2 \pm 0.3$ & 12 & $2.4 \pm 0.2$ & 4 \\
\hline
\end{tabular}

